Forthcoming in the Journal of Human Development and Capabilities. This is the accepted manuscript. Please cite the published version.

https://doi.org/10.1080/19452829.2020.1869190

\title{
Animal Capabilities and Freedom in the City
}

Acknowledgments. Thanks to the audience at the meeting of the 2019 meeting of HDCA in London and my co-panelists Amy T. Lynch, Jeremy Bendik-Keymer and Martha Nussbaum. I'm especially indebted to careful and detailed comments by an anonymous referee for this journal.

\footnotetext{
Abstract. Animals who live in cities must coexist with us. They are, as a result, entitled to the conditions of their flourishing. This article argues that, as the boundaries of cities and urban areas expand, the boundaries of our conception of captivity should expand too. Urbanization can undermine animals' freedoms, hence their ability to live good lives. I draw the implications of an account of "pervasive captivity" against the background of the Capabilities Approach. I construe captivity, including that of urban animals, as affecting a range of animal capabilities, understood as freedoms, and I address some tensions within Nussbaum's treatment of humananimal conflicts. Using the Capabilities Approach as a guide, I will attempt to motivate a convergence between habitat preservation in urbanized environments, urban design guided by justice, and the individual freedoms of animals.
} 
Cities bring people together from different ethnic, racial, economic, and religious backgrounds. Entrenched suspicions often divide them, and these suspicions can be either diminished or augmented by the layout of urban space. Urban architecture creates ways of living, sometimes fostering friendship, sometimes reinforcing fear. (Nussbaum 2013, 328)

\section{Introduction}

We live surrounded by fellow creatures. The city acts as a magnet for many species by the opportunities it affords, including food, shelter, warmer temperatures, and protection from predators. Cities also come with increased risks and new sources of stress or death: collisions with high-rise buildings, windows and cars, poisoning and pollution, killing and relocation, loud noise and artificial light. Many species, however, have found cities and suburbs worth the trouble. Rats, pigeons, geese, mallards, raccoons, possums, squirrels, cougars, bears, deer, coyotes in North America, macaques and sacred cows across India, baboons in Cape Town, or leopards in Mumbai, among many others, seem to thrive in urban areas or at least tolerate them more than one might suspect, as urban sprawl expands and opportunities flourish. Urban animals include feral and stray animals (cats, dogs, pigs, horses, etc.), scavengers, some of whom are considered 'pests' or 'vermin,' and other native and nonnative animals whose habitat or migration overlaps or intersects with urban areas. In this article, I draw on previous work (Delon 2018; 2020) to argue that the Capabilities Approach ${ }^{1}$ can help to illuminate the harms we cause to urban animals by expanding how we understand the scope of captivity. By diminishing freedom, urbanization can diminish

\footnotetext{
${ }^{1}$ Hereafter I mostly refer to the Capabilities Approach as 'the Approach' or by the acronym 'CA'.
} 
animal capabilities. At the same time cities create new opportunities for fellowship and flourishing. The question is not whether we should let animals live with us in the city, but how to foster the conditions of coexistence that align with the goals of justice across species.

In the first section, I articulate the connections between animal agency, freedom, captivity and the good. In section 2, I introduce the notion of pervasive captivity and consider how the criteria of captivity apply to urban animals. In section 3, I illustrate my account of pervasive captivity with a range of examples. In section 4, I clarify the relation between captivity, well-being, and adaptive preferences. In section 5, I discuss the implications of my account of pervasive captivity for fostering interspecies justice in the urban context against the background of CA.

\section{Freedom and captivity}

\subsection{Agency and the good life}

Agency has always been at the core of the Capabilities Approach to human development, as well as its application to nonhuman animals. CA "treats animals as subjects and agents, not just as objects of compassion". (2006, 351: cf. Wichert and Nussbaum 2019) The emphasis on animal agency brings out how freedom undergirds the whole list of capabilities, while accommodating the speciesspecific needs of different species given "the variety of animal capacities and activities" (2006, 94). Because of this focus, CA seems well poised to account for the harms and injustice of many forms of captivity.

Captivity deprives humans or animals of many goods and opportunities. Crucially, it prevents agents them from doing certain things. There is, for these reasons, a commonly held presumption 
against detaining humans or animals without adequate justification. ${ }^{2}$ Captivity is a deprivation of freedom, which is valuable, and it is wrong to deprive someone of something valuable without adequate justification, the thought goes. If freedom is valuable for animals, then keeping them captive causes them a pro tanto harm. From the standpoint of justice, it is wrong to them; captivity violates an entitlement or claim they hold against moral agents. For the purposes of this article, I assume that sentient animals can exercise some control over what to do, when, and where and with whom to do it, and have a morally significant interest in exercising such control. That is, many animals are agents and exercising their agency is a part of the good life for them.

Recognizing animal agency has important consequences. We should value agency, or a certain form of it, in other species like we value it, or that certain form, in humans (Sebo 2017). Since much of our agency is not fully rational, either we only have reason to value human agency in a limited range of circumstances, or we have reason to value agency that is not uniquely human. When we appreciate that the freedom to live our own lives matters to us, and not just by dint of its instrumental benefits, we value the basic experience of human agency. And so, analogously, we can see other animals as capable of valuing freedom besides avoiding pain and seeking pleasure.

Freedom is valuable beyond what it enables us to do. We would value it even if what it enables us to do could done for us. Recognizing this value need not commit us to claiming that freedom is either merely instrumentally or intrinsically valuable. First, according to Schmidt (2015), freedom can be "non-specifically instrumentally valuable." That is, it is a means to other goods that cannot always be identified in advance and is therefore not easily substitutable. So, even if freedom is not intrinsically valuable, its instrumental relation to intrinsic goods such as pleasure, health or

\footnotetext{
${ }^{2}$ See Jamieson (2003), chapters 11 and 12, and Rachels (1976).
} 
socialization can be such that there are few if any alternative means equally conducive to those goods. Another intermediate way of valuing freedom is as a constitutive a part of a good life (Gruen 2002). Curtailed freedom undermines the material conditions constitutive of a good life, including the physical and social environments central to flourishing, from access to territory, resources, mates and companions to opportunities for play and exploration. So, even if we could provide captive animals with all the instrumental benefits of freedom, and even if animals didn't value freedom intrinsically, captivity would still undermine the materials conditions of a good life by impairing their ability to do by themselves what matters to them. Henceforth I consider animal freedom as (at least) non-specifically instrumentally valuable and constitutively valuable, helping us to see what is wrong with captivity itself even for animals who presumably lack an intrinsic interest in it (say, because they lack the required faculties, rational autonomy or metacognition, to reflect on their desires and frame and revise their own conception of the good life) (pace Cochrane 2009).

A richer conception of animal well-being or flourishing that makes room for the significance of agency brings into focus more complex and varied forms of needs, desires, frustrations, cares and enjoyment than a thin assessment of welfare in terms of restricted preference testing, physiological indicators and basic biological health and integrity, and is thus rife with ethical implications, especially with respect to captivity.

\subsection{The concept of captivity}

Captivity is a state of un-freedom: along some or multiple dimensions, being deprived of freedom—to move around, socialize, hide, forage, mate, make choices of one's own, etc.—and

\footnotetext{
3 A surprisingly rather recent development in animal ethics. The first and only volume, to my knowledge, specifically dedicated to the ethics of captivity and its many forms is Gruen (2014a).
} 
prevented from exercising one's autonomy. Drawing on Gruen (2011), we can list three joint conditions of captivity: confinement, control, and dependence. ${ }^{4}$

To hold someone captive is to deny her a variety of goods and to frustrate her interests in a variety of ways. Though conditions of captivity vary considerably, I think it is most useful to think of captivity as a condition in which a being is confined and controlled and is reliant on those in control to satisfy her basic needs. (Gruen 2011, 133) ${ }^{5}$

Individually necessary, jointly sufficient, these three conditions can also be mutually reinforcing. Captivity involves, alongside spatial confinement, a specific type of restriction involving domination, or egregiously asymmetric power. Captors confine and control captives, thus diminishing not just their spatial mobility but their agency, their ability to determine how to behave, act and live. Doing so, captors rely on and increase a captive's dependence.

Not every external obstacle is a source of unfreedom, if it is under no moral agent's control to remove or prevent it (Schmidt 2016, 188-9). We are concerned primarily with man-made sources of restrictions that are under some moral agents' control, and secondarily with sources that are under their control whether or not they caused them in the first place. It is, moreover, the type of restrictions that matters. Captivity occurs when a member of a particular kind is subject to significant restrictions of their options relative to the relevant standard of well-being for members of that kind (CA also places opportunities or options for flourishing, relative to one's kind, as the

${ }^{4}$ I discuss Gruen's account at length in Delon (2020).

${ }_{5}^{5}$ Gruen specifies that the captive must be a "normally functioning adult" to avoid the implication that adults with severe cognitive disabilities and children are captive. As I argue elsewhere (Delon 2020), it's a bullet we can bite. 
center of justice) (see in particular Nussbaum 2006, 94; 357-366). By altering our options, captivity can interfere with the exercise of our autonomy, which I have assumed is more than merely instrumentally valuable. If and insofar as other creatures also have some form or degree of autonomy (capacity to exercise control and make choices), and an interest in exercising such autonomy, then captivity can interfere with something in which they have a morally significant interest.

The significance of restrictions is to be understood in reference to a relevant standard, such as a species norm, intrinsic abilities, a prior baseline, or another appropriate comparison class. In CA, (duly evaluated) species norms will be the primary benchmark for judging whether a creature has decent opportunities for flourishing (Nussbaum 2006, 357-372). To illustrate, whether animals still have viable counterpart populations in other habitats or whether their biology has been irreversibly altered are factors that determine which standard to pick. One plausible baseline for evaluating the freedom of animals whose habitats are altered is how members of the closest corresponding population fared before urbanization, combined with knowledge of their range of species-typical behaviors and facts about the current population. The assessment is compatible with urbanized populations having developed adaptations (cognitive, behavioral or physiological) that distinguish them from their rural counterparts. What matters is to find a standard of flourishing that an animal can achieve without changing the kinds of creature they are. An account of captivity must not be so broad that any limit on autonomy (e.g., legal coercion; emergency medical care) makes one captive, or so narrow as to preclude a priori the captivity of beings without an intrinsic interest in autonomy (e.g., children, nonhuman animals).

Let us take stock. Captivity typically involves abnormal restrictions of freedom construed as opportunity (or options) relative to appropriate standards. And by depriving one of freedom, which 
is non-specifically valuable as a non-substitutable means to or constitutive of a good life, it impairs one's ability to live a good life. If other creatures are owed a good life as a matter of justice, then we owe them consideration of their interests in staying free of such restrictions. With this account in hand, I now argue that animal captivity is pervasively induced—voluntarily, negligently or recklessly_by human encroachment upon animal habitats.

\section{Pervasive animal captivity and capabilities ${ }^{6}$}

Once we recognize animal agency across a wide range of habitats and species, we start to see that our actions have consequences that permeate all spheres of animal life and end up diminishing the agency of many. In the Anthropocene, human production, consumption and development have a pervasive impact on species, habitats, ecosystems, landscapes, and the climate. We restrict animals' agency by keeping them confined in cages, crates and enclosures, but also by limiting what they can do outside of visible captivity. Habitat destruction and fragmentation, unfettered development, and climate change affect the conditions under which many species evolved. Since even protected areas like natural reserves are heavily monitored, regulated and spatially bounded, there are few tracts of land, air or sea where animals are not to some extent confined, controlled and dependent on human agency. Just as human/nonhuman boundaries collapse along the agency spectrum, so does the captive/wild boundary (cf. Bekoff and Pierce 2017; Donaldson and Kymlicka 2016; Jamieson 2017). Human communities alter landscapes such that they constrain animals' behavior, migration, and hunting grounds, through fences, traps, and other barriers, potentially making them dependent on those changes, and thereby exercising control over those populations. Pervasive captivity thus

\footnotetext{
${ }^{6}$ This section borrows from Delon (2018).
} 
emerges in natural parks, wildlife reserves, and rural farming communities because there are few if any alternative options for securing the goods to which those freedoms are conducive or of which they are constitutive.

Many wild animals, including urban animals, are captive on the above account. The verdict is counterintuitive, yet we must reckon with the expansion of the boundaries of captivity. Gruen's account of captivity accords with our pre-theoretical judgments about cases: namely, that animals in zoos, circuses, labs, farms, sanctuaries, shelters, houses, and parks are captive. The account also explains why captivity can be harmful, by depriving one of opportunities to access, enjoy or do certain things, and to do so by oneself. By the same token, captivity is more pervasive than our pretheoretical judgments assume. Nussbaum $(2006,374)$ recognized that wild animals and their opportunities were already irreversibly and pervasively affected by human activity. Moreover, in the name of securing capabilities among species, and the responsibilities that follow from our impact, she suggested that some wild animals may have to live under greater human supervision and control, including zoos (375-380). Nussbaum argues that we have both duties to protect habitats and duties of material aid - "the only question should be how to balance them against appropriate respect for the autonomy of a species." (374) I return to the issue, and whether Nussbaum can resolve the tension, in Section 5.

Now consider each of Gruen's criteria as they apply to at least some urban wildlife.

(i) Confined: their range of movement is severely restricted to, or between, urban areas; their migration can be constrained by features of the urban landscape (buildings, roads, bridges, power plants, wires, fences, lights, etc.). Because the restrictions are severe relative to their natural range, many populations are confined, not just excluded. 
(ii) Controlled: individuals, organizations, institutions, practices, patterns of behavior shape and constrain, locally or globally, individually or collectively, their options (e.g., where to travel, what to eat, where to live, whether, when and with whom to mate). Again, control is understood relative to a natural or otherwise relevant baseline.

(iii) Dependent: in part because of (i) and (ii), urban animals are reliant on human provision, food scraps and waste as well as ecological niches for meeting their basic needs, including reproduction (altered by culling and contraception).

Along each dimension, animals' options can be restricted. There is, of course, variability in both degree and kind depending on species and environment. Cities are not homogenous, each being home to a diversity of species, places and relationships. Whether animals will avoid, tolerate or seek out humans is also a matter of personality, with great variability across species, regions, habitats, and individuals (Gehrt et al. 2011; Lowry et al. 2013; Miranda et al. 2013). Nonetheless, we can pick out the defining features of captivity. Many urban animals are confined, physically, spatially and behaviorally. Urbanization subjects them to control, both deliberate and accidental, over their agency, habitat, or simply whether, where and how long they live. Finally, they are dependent on the environment they have adapted to and on human tolerance or assistance, thus foreclosing alternatives. Moreover, as urbanization alters individuals, populations or species, they can become constitutionally captive (see section 4).

\section{Examples}

Urbanization involves destruction, fragmentation and alteration of habitat, and animals killed, poisoned, repelled, trapped and relocated, excluded by fences, wires, roads, and impasses, confined to protected places, or accommodated by nesting sites, underpasses, corridors, and road warning 
signs It affects animals' range of movement and choice, for exploring, foraging, mating, nesting, migrating, resting, etc. Two important outcomes are avoidance and scavenging (Palmer 2003a). They point in opposite directions, confining animals either outside or within human range (with intermediate cases such as coyotes). Human communities describe scavengers such pigeons, rats, and raccoons "as colonizers of urban areas, rather than as colonized beings moving in spaces they formerly occupied" and are thus considered "unwelcome" pests or vermin (Palmer 2003a, 51) because of their "unruliness" (Palmer here draws on Foucault). These animals were not bred for human purposes, and their behavior can be disrupting (e.g., urination and defecation, smelling, rummaging in trashcans, eating refuse, unrestrained whereabouts). Eventually, hostile responses to unruliness curtail their options even further.

Many scavengers depend on human provision, whether directly (feeding) or indirectly (leftovers and garbage). For example, mallards on a riverbank benefit "from the warmer urban climate and longer ice-free periods" and humans welcome them. (Palmer 2003a, 52). Initially very adaptable, they adjust to humans, becoming not only more docile and less fearful, but also increasingly reliant on them for their basic needs. The relationship, however, is asymmetric. If humans withdrew care, the ducks would suffer; humans would not. Dependence thus creates vulnerability when adaptability is traded off for docility. The story is similar for Eastern gray squirrels and street pigeons. Feeding them used to be quasi-institutionalized in some places until it became illegal Jerolmack 2013; Palmer 2003b; Benson 2013). As they became dependent on human provision, these animals lost options to escape, evolving in particular niches and losing skills required to adapt to unexpected changes, eventually getting trapped in their niche: confined where their odds of survival are highest; controlled by "external practices" (confinement, isolation, eviction, castration, mutilations; Palmer 2001, 355); and dependent, partly as a result of confinement and control. 
On the other hand, we should not generalize. Animals that best succeed are opportunists or generalists with flexible diets and dispositions to problem-solve, such as coyotes (Gehrt 2004, Gehrt et al. 2011, Lowry et al. 2013). Niche specialists, introduced exotics and some feral animals can be less flexible, hence more vulnerable to change (Donaldson and Kymlicka 2011, 221-226). In the city, boldness and curiosity will pay off for many (e.g., raccoons, house sparrows); neophobia and wariness for others (e.g., coyotes, many birds). Coyote expert Stanley Gehrt and his colleagues note that

the urban coyote appears to be behaviorally misanthropic (e.g., strong spatial and temporal avoidance of people) but demographically synanthropic (e.g., elevated survival and density, possibly reproduction). This unique combination has likely played an important role in the success of coyotes in urban areas (Gehrt et al. 2011, 17).

Nonetheless, coyotes are captive insofar as they are precluded from avoiding us for lack of alternatives; monitored and managed by animal control and wildlife services; and reliant on urban areas (indeed they owe their success to their "demographical synanthropy"). ${ }^{7}$

Let me mention two more examples of pervasive captivity.

The Santa Monica Mountains in California_extending from the Pacific Coast near Malibu through the Hollywood Hills to Griffith Park in Los Angeles—are teeming with wildlife, including large carnivores like mountain lions (also known as cougar, panther, puma or catamount). These animals

\footnotetext{
${ }^{7}$ Recent evidence suggests that in coyote parents who experience extended contact with humans, habituation leads, through phenotypic plasticity, to the transfer of fearlessness to their offspring over the course of just a couple generations. Each litter of pups was bolder than the previous litter (Schell et al. 2018), both an asset and a liability in risky areas.
} 
can cause damage to private property, pets and livestock, as their habitat cuts across both public and private land and their territory is encroached upon by suburban sprawl. The mountain range is bounded by the ocean to the south and the Hollywood Freeway to the north and divided by I-405. "Just as the roads keep native lions in," writes Dana Goodyear in the New Yorker, "they also keep outside lions from entering ... Lush but confined, the mountains are a cushy prison” $(2017,44)$ where inbreeding spreads, putting the cats on the verge of extinction (Riley et al. 2006), and their hunting grounds are limited, leading to conflicts with humans and their pets (Gullo et al. 1998). P22, a cat who came to reside in Griffith Park after crossing highways, has to risk death by crossing roads again or wait for daring mates to cross. When stuck like P-22, males are unable to mate, compete fiercely with other males, get killed by cars or rat poison.

For the Capabilities theorist, the cat's opportunities for flourishing are clearly, and unjustly, diminished. Conflicts are real but must be read against the backdrop of restrictions induced by habitat fragmentation, haphazard development, prejudice, and misinformation. Mountain lions are subjected to severe geographical confinement and control (tagging, monitoring, and culling) and depend on those who control them (National Park Service, wildlife services, private and public stakeholders). Coexistence with a view to flourishing at least requires securing the animals' capabilities with relatively simple infrastructure such as dedicated crossings, bridges, and underpasses (Goodyear 2017, 51; Riley et al. 2006; Donaldson and Kymlicka 2011, 246). ${ }^{8}$

\footnotetext{
8 Another interesting example are the bobcats in the city of Thousand Oaks who, between 2002 and 2005, were "cut off from the rest of the population by Route 101" and as a result "suffered from an epidemic of mange" (especially those whose immune systems had been weakened by eating poisoned rodents). Ironically,
} 
Street pigeons are nonnative feral birds and appear to thrive in urbanized environments. Yet they are captive. They are largely dependent on human provision, subject to human control, and confined to urban spaces. Sure, they have free mobility. Yet we consider homer pigeons captives even though they can, by design, be let free and return home by themselves. Pigeons have become urbanized and captive as a result of their own agency. Their ancestors, Rock doves, partly domesticated themselves; then, escaped pigeons started to populate cities. Dependence, control and confinement ensued.

Case in point, the pigeons of Trafalgar Square, London, and Piazza San Marco, Venice are "objectively different than most other street pigeons" in that "they have been tamed [and] become fully dependent on people for food and have stopped scavenging”, writes sociologist Colin Jerolmack $(2013,74)$ With dependence, their status changed: "Until recently, both sites famously hosted vendors who sold pigeon feed. It was a tradition for visitors to allow the ravenous flocks of pigeons to land on their shoulders and eat from their hands." (6) Then both cities evicted the vendors, labelled as rats with wings, and banned feeding. Because pigeons are now considered nuisance animals, many cities implement controls such as futile anti-pigeon tactics (plastic owls, spikes, sounds of raptors, 'No Feeding' signs, shooting, electrocuting, poisoning, etc.) or criminalization of feeding. Arguably, pigeons are not obviously confined. Still, we can see attempts to remove them from their "improper" place as attempts to confine them to their (imaginary) “proper" place (Philo 1998, Philo and Wilbert 2000). "[L]ike weeds in the cracks of pavement," writes Jerolmack, "pigeons represent chaotic, untamed nature in spaces designated for humans"

the resulting bottleneck may have helped them adapt quickly to the challenge. Genetic fragmentation can, over time, drive evolutionary adaptations. (Schilthuizen 2018, 118; cf. Serieys et al. 2015; Riley et al. 2007) 
(73). However, because they are considered "out of place" and yet far removed from the wild, there are few places for them to be. They are, so to speak, "a 'homeless' species, surviving in the urban interstices off of society's occasional generosity and its refuse.” (ibid.)

Many urban animals are confined, subjected to control, and dependent. These three mutually reinforcing aspects of their captivity diminish their opportunities for flourishing and to be the agents of their own lives. Degrees and types of restrictions yield varying degrees and types of captivity, as do various forms of life and dispositions to adapt. Mountain lions are severely confined and controlled but not heavily dependent. Pigeons are quite dependent and controlled, but less obviously confined. Both, however, like coyotes, raccoons, mallards and many others have their agency impaired to some degree as a result of urbanization. In the next section I say more about the harmfulness of captivity.

\section{Captivity and adaptive preferences}

On my account of captivity, many capabilities (henceforth listed as $\mathrm{C} 1-10^{9}$ ) appear directly relevant to animal freedom. Confinement relates to mobility as a central aspect of Bodily Integrity (C3) as well as Senses, Imagination, and Thought (C4), for which we should ask "what choices and areas of freedom seem most important to each [type of animal]" (2006, 396), leading us to "reject confinement and to regulate the places in which animals of all kinds are kept for spaciousness, light and shade, and the variety of opportunities they offer the animal for a range of characteristic activities.” (397) Control

\footnotetext{
9 1. Life; 2. Bodily Health; 3. Bodily Integrity; 4. Sense, Imagination, and Thought; 5. Emotions; 6. Practical Reason; 7. Affiliation; 8. Other Species; 9. Play; 10. Control over One’s Environment (Nussbaum 2006, 392 401).
} 
thus relates to C4, as well as, obviously, Control over One's Environment (C10), Affiliation (C7) and Play (C9). As for dependence, it can reflect a diminished capacity with respect to $\mathrm{C} 10$ or even $\mathrm{C} 7$, insofar as attention to dignity is paramount in how animals should be allowed to shape their relations to others. Dependence also clearly increases as animals lose the ability to exercise reproductive control, a potentially central aspect of C3 and C7, whether by way of sterilization, contraception, or the indirect alteration of reproductive and hormonal schedules. ${ }^{10}$

However, CA does not straightforwardly imply that pervasive captivity is wrong. Why? Consider an objection to the idea of pervasive captivity, according to which, because animals are not worse off in cities and captivity is necessarily harmful, they are not captive. For instance, increased access to food sources enhances coyotes' freedom from hunger; cities provide all sorts of underground dens and structures protecting prey animals from their natural predators. And many animals, who retain some possibility of escape, appear to assent to living in urban areas. From the standpoint of CA, city life can even be a way of securing a threshold level of capabilities along various dimensions of well-being (especially C1-3: life, health and integrity). According to most theories of wellbeing - objective-list (i), hedonistic (ii) and desire-fulfilment (iii) theories (Parfit 1987, Appendix I) - we could claim that urban animals are not worse off, because: on objective-list theories, they fare well enough along other dimensions of well-being, such as health, integrity, pleasure, or social relations; on hedonism, their balance of pleasant experiences is net positive; and on desirefulfilment theories, most of the animals' desires or preferences are satisfied (or else they would attempt to migrate out of the city). CA, as we shall see, will assess how well animals are doing on an

\footnotetext{
${ }^{10}$ We could, however, push animals into a low-reproductive form of the relevant functionings in order to make them and their offspring less dependent on human provision. Thanks to anonymous reviewer.
} 
objective basis, but can explain better than alternatives why some of them are not doing as well as they could.

A possible response is to deny that all urban animals now flourish, even if they once did. The individual members of many species do not fare the best they could. For instance, street pigeons have shorter life-expectancies and higher mortality rates, suffer more from debilitating injuries, impairments, and diseases, and may be exposed to more direct threats (e.g., hawks, owls, cats, humans) than their rural counterparts. A recent study by Tuul Sepp and colleagues canvasses the possible relation between urban life and rates of cancer among urban animals. Among other things, wild animals affected by urbanization processes are faced with "increased exposure to an assortment of pollutants (e.g. chemicals, light and noise), novel types of food and new infections", all of which "are associated with an increased probability of developing cancerous neoplasias". $(2019,1)$ Despite a dearth of studies, the authors hypothesize a variety of factors. Habitat fragmentation, creating poorly connected pockets of population, could be one. Islands of populations can foster the spread of pathogens, then when specimens manage to move between pockets, they carry those pathogens to unexposed, non-adapted populations. ${ }^{11}$ Moreover, by restricting gene flow between populations, physical urban barriers can lower genetic diversity, which increases vulnerability to pathogens and is also associated with inbreeding and cancer. Other possible factors include diet change and access to processed foods; higher exposure to chemical pollution causing mutations, birth defects, and weaker immune systems; light and noise pollutions, which disrupt sleep patterns, suppress certain hormones and cause stress. On the other hand, by

11 This also illustrates the ambivalent effects of corridors, which can break down "delicate adaptations" (Schilthuizen 2018, 237), 
increasing average life expectancy urbanization mechanically increases cancer by limiting other causes of death before cancers appear. (ibid.) Reduced predation exposure also has benefits. "The presence of old, sick, and handicapped animals ... suggests that predation risk is low for many populations of urban animals". This, in turn, reduces vigilance behavior and stress levels and increases time spent foraging (Animal Ethics 2019). Many species, such as rats and mice, adjust well to pervasive captivity, for instance white-footed mice (Peromyscus leucopus) in New York:

Although they are imprisoned in these parks [e.g. Willow Lake in Queens] (they will only travel under cover of vegetation and most parks are not connected by anything that's green), the mice are doing quite well there, especially in the smallest parks, which are too small to support predators like owls or foxes. (Schilthuizen 2018, 114)

Whether urbanization improves wild animal well-being depends on many factors, including speciesspecific adaptability, population structure, local features, and human behavior. At any rate, it would be premature to conclude, from the sole presence of wild animals amidst us, that their overall wellbeing is thereby improved relative to their rural counterparts. In some cases, we simply cannot compare the well-being of urban animals with that of their counterparts. Street pigeons, for instance, never really existed in the wild. (Jerolmack 2013,10) But this doesn't mean we cannot compare their needs to a realistic benchmark of improved conditions such as the capability threshold required by justice according to Nussbaum.

More importantly, these facts give but a snapshot of urban animals' flourishing, and a biased one at that. What we can observe is limited by survivor bias. We observe examples of "those life forms that were pre-adapted, variable, or simply lucky enough to evolve and survive. For each successful urban species there are dozens of other species that could not adapt to city life and disappeared." (Schilthuizen 2018, 244-5) 
As we know, however, humans and animals can develop adaptive preferences (Elster 1983; Nussbaum 2001a, chapter 2; 2006, 343-4). These are preferences formed or changed, typically subconsciously, under bad or unjust background conditions such as profoundly limited sets of options. Why should we be attentive to adaptive preferences?

many of the deformed preferences emerge only in diseased relationships between animals and humans.... Creatures accustomed to captivity may never be able to learn to live in the wild. Simply aggregating all these deformed preferences [as utilitarianism does], without winnowing out those that are the product of unjust background conditions ... is a recipe for endorsing an unjust status quo. (2006: 344)

In CA, when an animal's preferences are adaptive, the animal's apparent decisions to stay, or apparent assent to, a situation may not reflect their objective well-being. The Approach supplies a non-subjective metric of well-being which avoids taking choices at face value when they are the product of unjust material conditions.

Captivity can diminish a creature's well-being despite appearances to the contrary. CA seems poised to account for the harm of captivity, by stressing the conditions under which desires and preferences are formed and expressed, whereas a subjectivist theory of well-being that doesn't account for adaptive preferences, can mistake actual cases of oppression and subjugation for desirable circumstances. Understanding animal well-being in terms of capabilities shows why animals with adaptive preferences are in fact worse-off.

Incidentally, Nussbaum makes a similar point about immigrants forced to work in the city: "since most new immigrants found work opportunities in the cities rather than in rural areas, one could not assume that their choice to live in a city reflects a preference for urban life conditions." (2013, 357) Analogously, if urban animals have formed or changed preferences under subpar conditions, 
such as the lack of adequate habitat to exercise their capacities freely, having preferences that track their situation provides little evidence that they would otherwise maintain them. Animals adapted to urban life may have adjusted their preferences toward something suboptimal. Coyotes in Chicago and other major U.S. cities have become tamer and bolder, partly at their own expense when, seen as unwelcome invaders and acting more aggressively, they are trapped and relocated or, worse, killed, despite the extreme rarity of incidents. Concluding that many animals have adapted to (and benefit from) such conditions because they appear to prefer them is reverting the direction of explanation. Many of these animals had to adapt to changing conditions, under which they formed their current preferences. Adaptation explains many of their current preferences; they did necessarily not adapt in order to satisfy their preferences.

Not all preference changes, even under suboptimal conditions, are illegitimate or inauthentic. Even if an animal's preference for an environment is only partially indicative of the latter's adequacy, the preference need not be a suboptimal adaptation. Even if it were, it need not be prudentially bad for the animal to have it, if satisfying that preference is overall conducive to greater well-being (again, urban animals' adaptations often pay off). Still, at least some of the preferences of urban animals are suboptimal adaptations to external constraints, environmental change, and urban stressors. Because their range of options can be significantly restricted (i.e. capabilities diminished), we should expect some such preferences to be suboptimal adaptations.

Indeed, there is good reason to suspect that adaptive preferences and captivity can be coconstitutive, as with the so-called Stockholm syndrome, whereby hostages end up forming preferences for their condition and/or attachment to, sympathy with or endorsement of the cause of their captors. When victims lack options, they change their preferences, including their preference for escape. Coping mechanisms can be effective ways to compensate for welfare loss 
under unfavorable conditions (e.g. pacing in response to stress, anxiety, and boredom in zoos), but they are not reliable indicators of well-being. Instead, adaptive preferences signal impaired autonomy, since the newly formed preferences are externally constrained as a response to circumstances over which agents have little control.

Adaptive preferences as such are not necessarily prudentially bad or irrational (Barnes 2009; Bruckner 2009; Terlazzo 2017). However, the conditions of their formation are indicative and should give pause, especially if, as with animals, we cannot collect first person testimony and, as Nussbaum puts it, the “interpretation of animals' preferences is fraught with obscurity and difficulty" (2006, 343). Thus, preference testing is informative but does not tell us much about the value of the status quo if current options are severely limited. What animals prefer under the circumstances is at best a partial indicator of the choices they would make in realistically better conditions. We should also be careful not to conflate population levels with individual well-being. Many of the adaptations that facilitate urban life are not prudentially beneficial or harmful, even when they support viable populations. Mutations and genetic drift are random processes irrelevant to well-being.

In sum, just because rats, pigeons and coyotes appear to thrive among us does not mean that we cannot do better and enhance their freedoms. The relevant baseline for identifying relevant needs and/or preferences is not a romanticized rural life but an urban environment that can support their freedom.

The case of urban animals thus brings out a tension between the claim that pervasive captivity diminishes capabilities and the idea of cushy captivity, according to which some components of the well-being of wild animals is improved in the urban environment, because of the availability of food and shelter, among other things. However, seeing pervasive captivity through the lens of capabilities 
can help resolve the tension. If pervasive captivity is a form of un-freedom, or failure to secure a threshold level of animal capabilities, then CA provides a benchmark for evaluating whether and how animals in urban environments are being made more or less able to live in ways that accord with their species norm, despite some degree of confinement, control, and dependence.

A helpful idea to make sense of these possibilities is that of constitutional captivity. Dog cognition expert Alexandra Horowitz writes: “[dogs”] brain structure, and, as a correlate, cognition, has been altered. They no longer have the perceptual acuity to survive outside of human civilization.” (2014, 13). What it means to flourish as a domestic dog (Canis familiaris), as opposed to their wolf ancestors (Canis lupus), entails captivity. Dogs were "selected to be kept" and are "dependent on us for food and protection" (18). Yet individually they can be subject to different forms of confinement and restriction (physical, social, sexual, sensory, dietary). We can enhance their freedom within constitutional captivity. Likewise, I suggest, we can enhance the freedom of wild animals within the city. As I discuss in the next section, this is the needle that Nussbaum's approach to interspecies justice has to thread.

With these qualifications in mind, we can conclude that apparent preferences do not reliably indicate whether captivity is good or bad for a creature, but also that captivity need not be all things considered harmful and unjust. This result is important for the sake of fostering interspecies justice for it may be that we can no longer avoid pervasive captivity, yet we should go further and promote animal freedoms rather than abide by the status quo.

\section{Capabilities and coexistence in the city}


This section outlines some normative implications of my account in light of Nussbaum's application of CA to animals. ${ }^{12}$ While my account of captivity has not presupposed CA, their alignment reveals some novel implications. I already mentioned early on that freedom is constitutive of a good life. The Approach construes all central capabilities as primarily opportunity freedoms as a necessary means of the liberal preservation of autonomy. CA has two main components that allow me to draw these implications: a theory of capabilities as an objective measure of well-being and a sufficientarian conception of justice, whereby subjects of justice have entitlements to have their capabilities ensured above a certain threshold. The theory can then be used to assess changes in animals' well-being that do or do not give rise to claims of justice.

However, whereas the liberal commitment to autonomy is central to human development, Nussbaum is more sanguine about animals:

In the human case, one way we respect autonomy is to focus on capability, not functioning. ... for children, and in some cases for people with lifelong mental disabilities, it [is] appropriate to aim at functioning instead, or to leave choice-making to a guardian. In general, paternalistic treatment is appropriate wherever the individual's capacity for choice

\footnotetext{
${ }^{12}$ Nussbaum's emphasis on dignity also lends itself to a powerful critique of many forms of captivity, especially zoos, aquaria, marine parks and circuses; While improved zoos may be acceptable for certain species (2006, 375-380), Wichert and Nussbaum (2019) think captivity is incompatible with cetaceans' flourishing and dignity, at least not as we see it in captive facilities such as SeaWorld. It's less clear, however, whether pervasive captivity runs afoul of dignity. For a discussion of the relation between dignity and captivity, including of Nussbaum's account, see Gruen $(2014 ; 2018)$.
} 
and autonomy is compromised. This principle suggests that paternalism is usually appropriate when we are dealing with nonhuman animals. $(2006,375)$

Nussbaum qualifies that conclusion by noting that "species autonomy, in pursuit of flourishing, is part of the good for nonhuman animals," and that paternalism must be sensitive "to the different forms of flourishing that different species pursue".

A creature has positive well-being when that they are free to achieve a greater combination of functionings, even though we may sometimes be justified in securing functionings, especially when their flourishing is vulnerable to our agency. Reckoning with vulnerability is also central to CA. "Agency and support are connected: it is on account of their capacity for activity and striving that human beings are entitled to support for their vulnerability" (Nussbaum 2013, 120) and "all animals [are] entitled to support for their agency and striving." (121) There is, thus, a range of possible good lives, not a single top-down conception, that creatures should be able to access.

As noted, one capability seems especially relevant to the present argument:

10. Control over One's Environment. In the human case ... [t] he political is defined in terms of active citizenship and rights of political participation.... On the material side ... certain sorts of protection for property rights and employment rights, including the right to form unions and the free choice of occupation. For nonhuman animals, the analogue to property rights is respect for the territorial integrity of their habitat ... The analogue to work rights is the right of laboring animals to dignified and respectful labor conditions. $(2006,400)$

Freedom undergirds the whole list of capabilities, each capability consisting in the ability, through internal abilities and external resources, opportunities and protections, to achieve a function, but C10 brings into focus the moral and political significance of pervasive captivity. The central freedoms of some urban animals are below the acceptable threshold of justice, and C10 makes it all 
the more salient if my account of their captivity is correct. Insofar as we owe it to other creatures to secure the conditions of their capabilities, when we diminish urban animals' capabilities below a minimum threshold, we wrong them. Optimizing freedom by reducing captivity can, for many such creatures, bring them closer to the threshold of justice. This may not be a sufficient but is a necessary step to interspecies justice. At the very least, CA entails "a commitment to bring members of [a] species up to [their species specific] norm, even if special obstacles lie in the way of that" (Nussbaum 2006, 365).

Nussbaum advocates an "intelligent, respectful paternalism" $(2006,370)$ and "the gradual supplanting of the natural by the just" (400), and argues that, given our pervasive interference with natural processes and the natural obstacles to every creature's capabilities (including disease, disasters, and predation), we have positive duties to ensure the flourishing of creatures and to foster mutually respectful relationships among them. C8, Other Species, involves "being able to live with concern for and in relation to animals, plants, and the world of nature." C8 concerns, among other things, endangered species, wild animal well-being, and ecology. We should expect it to apply to relationships among urban animals too. Predation and competition do not stop when wild animals enter urban environments so these interspecies conflicts will also need to be addressed.

Setting aside the vexed question of interventions to relieve wild animal suffering (Delon and Purves 2018; on Nussbaum, cf. Cripps 2010; Hailwood 2012; Palmer 2010), if we agree that pervasive captivity threatens urban animals' freedom, and capabilities are constitutive of freedom, then an “intelligent, respectful paternalism” guided by justice should promote agency where possible. However, in the urban context, many different, coexisting forms of life need to autonomously pursue a good life, leading to conflicts, which CA also needs to adjudicate with a view to justice. 
The promotion of urban animals' freedom should therefore not be conflated with a preservation of their wildness and the elimination of human interference with animal agency.

On the other hand, Donaldson and Kymlicka $(2016,225)$ note, " $[\mathrm{t}]$ he fact that humans inevitably affect and interact with ever more animals does not alter the fact that animals' lives are still theirs to lead, and that human management and intervention is legitimate only insofar as it respects animals as intentional agents." Animals are agents and "shapers of lives" in CA too (Wichert and Nussbaum 2019). Nussbaum would be wrong to conclude that our entanglement gives us, not just responsibilities, but also dominion over other creatures. Thus, resolving the tension requires ways to concurrently promote agency and flourishing.

Perhaps one such way lies in Breena Holland's (2008) idea of a "sustainable ecological capacity," a "meta-capability" enabling each capability. Roughly, an adequate environment is instrumental to achieving capabilities, hence we must morally take account of how ecological systems, cycles, and processes affect the environmental impacts and experiences of people. The meta-capability complements the list of first-order capabilities by securing the conditions of their realization and expressing persons' rights to live in a balanced, protected and biodiverse environment. Holland argues that certain environmental conditions are instrumental to all human capabilities, necessary for the material goods, such as shelter, nourishment, and property that Nussbaum argues are instrumental to capabilities. While Holland's argument is about buman capabilities, the argument can extend to analogous conditions instrumental to the capabilities of other animals. As the case of urbanization shows, human and animal flourishing are entangled, and their relations are mediated by ecological sustainability. As we saw, restrictions on animals' freedom often result from structural, environmental or social constraints rather than intentional captivity. If so, urban creatures can clearly lack the environmental conditions of their capabilities. And so, by preserving and improving 
swaths of nature within urban environments, we can simultaneously promote ecological sustainability and individual animal flourishing.

Ecological sustainability, however, does not eliminate interspecies conflicts. Rats are great citydwellers, too. They swarm and thrive in drains, burrows, basements and attics, in the sewer and underground, feeding on leftovers and reproducing at vertiginous paces. Large cities like Chicago, Los Angeles and New York are testaments to rats' remarkable adaptations to urban ecosystems, as are exterminators and desperate attempts to control their populations. Many people consider them vermin. Rats urinate and defecate in our homes, gnaw through electric cables, carry diseases (bubonic plague, typhus, rabies, leptospirosis, etc.), mites, fleas, lice and ticks. Rats arrived on the continent with settlers. The history of the city is therefore that of rats, too (Sullivan 2004). They're no more or less out of place than the settlers were when they colonized North America.

Rats thus illustrate the ineliminability of conflict. Given the goal promoting justice for all creatures, [e]ven if we narrow the group of creatures [to sentient ones], there will very likely be pervasive conflicts, since creatures threaten one another's safety and since fostering the good of one creature may actually create a greater threat to another (Nussbaum 2001b, 1541).

Nussbaum goes on, It would be nice to think that rats could all be shipped off to a rat community where they could live untroubled lives without infecting or endangering other animals; something like this probably can be done with field mice ... But killing rats does not seem to be a heinous moral evil, and it may in many cases be the least of the evils. (ibid.; cf. 2006, 371; 385-8)

When "sterilization and other nonviolent methods" are not realistic, we may have no other choice than to kill rats. In these circumstances, pervasive captivity may seem like the least of their concern, 
except that such conflicts emerge when animals are trapped within human communities. Again, then, CA is committed to resolving this tension. Seeing rats as captive, then, casts our responsibility under a new light.

CA, while seeking a Rawlsian overlapping consensus, accepts the existence of ineliminable "tragic conflicts.” (Nussbaum 2000; 2006, 401-5). Yet it also demands that we seek to minimize such conflicts while acknowledging the reality of the harms (or costs) of such conflicts. CA is therefore deeply committed to fostering coexistence through reasonable accommodations. Nussbaum mentions sterilization but limiting the opportunities we afford rats in our homes is another, possibly more effective option (Donaldson and Kymlkica 2011, 246). Ironically, by making our spaces less attractive to rats we might make their captivity milder and less prone to harmful conflicts - rats are thus less captive at least with respect to control.

There is, thus, a central tension in the Approach that one may hope to resolve, between Nussbaum's focus on agency and fellowship, on the one hand, and her pragmatic emphasis on conflict resolution on the other. Instead, I will soon suggest, the former should guide our attempts to tamper the latter. Conflicts require some sort of intervention, which underscores a potential tension within CA, since it is committed both to leaving animals free to initiate their own activities and make their own choices, and to controlling their lives in ways that will help to secure their capabilities.

The tension is most salient in Nussbaum's uneasy treatment of paternalism (see e.g. Palmer 2010 for discussion). She starts by acknowledging the force of an "imagined argument" critiquing "benevolent despotism of humans over animals, supplying their needs", appealing to "the sovereignty of species" $(2006,373)$ Indeed, given the dignity of wild animals, overseeing their good at the cost of their freedom would run afoul of the commitments of CA, since "[p]art of what it is 
to flourish, for a creature, is to settle certain very important matters on its own, without human intervention, even of a benevolent sort." (ibid.) At the same time, precisely because capabilities are at stake, Nussbaum advocates for an "intelligent, respectful paternalism [that] cultivates spaces for choice", recognizing that "no treatment [of animals] is respectful that does not allow them to initiate activity on their own in some ways and to some degree”. (Nussbaum 2006, 378) Such paternalism, I suggest, should take the form of ecological institutional design involving, in part, public space design with a view to interspecies justice.

But let us note that Nussbaum is walking a fine line. The tension is real and the costs of holding fast onto both commitments non-negligible. Simply assuming the permissibility of paternalism, as intelligent and respectful it may be, risks treating animal agency more cheaply than one should, thus sacrificing a basic commitment of CA. The tension turns on the existence of cases where promoting components of well-being that are not agency-related comes at the expense of agency, and vice versa. Specifically, Nussbaum has repeatedly interpreted CA as precluding trade-offs between the ten capabilities on her list. They cannot be weighed against each other, and so justice requires guaranteeing, for each subject of justice, a minimum threshold of each capability. ${ }^{13}$ Yet in practice balancing seems inevitable. Reducing wild animal suffering, for instance, will necessarily impose restrictions on animal agency. A related question that stems from the present argument is, for instance, whether relocating animals to places where they are less confined, controlled, or dependent would foster their agency, and if so, whether other capabilities, all things considered, speak against such relocation. Relocated animals might have diminished well-being by some metric

\footnotetext{
${ }^{13}$ Nussbaum writes: "The capability approach insists from the start that the elements of life are plural and not single and thus that the core social entitlements are also plural. It would be a grave error to single out any one of the ten to bear the weight of indexing relative social position: all are minimum requirements of a life with dignity and all are distinct in quality." $(2006,84)$
} 
but be more free to live their lives according to the relevant species norm. In other words, CA does not settle a priori how to arbitrate between agency and well-being, each of which can involve prioritizing very different capabilities. ${ }^{14}$

Before concluding, let me comment on remarks that Nussbaum makes about public parks in order to make my recommendations more concrete. I suggest that protecting green places in urban environments can create a cross-species public space, which is conducive to the creation of crossspecies fellowship. In such spaces, animals can be less confined, controlled, and dependent, and therefore more autonomously set their own terms of engagement with us regarding when and how we can enter their lives. This possibility thus brings into focus the role of the ecological metacapability: a precondition of animal freedom in urban spaces is environmental conditions that are instrumental to the capabilities that these spaces can enable. Green urban spaces must therefore be designed as functioning habitats for such animals, not just for us. ${ }^{15}$

I am here broaching on remarks of Nussbaum (2013) in the context of her discussion of the role of emotions in building political equality. A subsection on Central Park in New York City resonates with some of my suggestions. Nussbaum's point is that "public space is of real importance" in "creating equal opportunity", and that public parks play a critical, if not sufficient, role in fashioning the material conditions that bring people together, reduce inequalities (e.g. of access to green spaces) and decrease envy (between poor and rich). Parks may "supply an escape valve that preserves the possibility of [human] friendship.” (Nussbaum 2013, 359) Parks can limit such "harmful passions", envy, fear and hostile shaming, but also create fellowship. Political equality "is

\footnotetext{
${ }^{14}$ Language in this paragraph is indebted to very helpful suggestions by an anonymous referee.

15 Thanks to an anonymous referee for helping me to frame this possibility.
} 
not just a matter of good laws and policies. Often it is at least as much a matter of the buildings one inhabits, the streets on which one walks, the way the light arcs down upon a neighbor's face, and a glimpse of the green spaces that beckon down the block." (377) These remarks, I think, would apply as well to the construction of urban spaces in which interspecies justice can be realized and, perhaps, interspecies friendship can emerge.

\section{Conclusion}

We need to coexist with urban wildlife. Urbanization affects animals' well-being, in particular their freedoms along several dimensions. I argued that many urban animals can be seen as captives, and that animals, as agents, have interests in freedom; it is a component of their well-being. CA is equipped to account for the harms and the injustice of captivity, including that of what I called pervasive captivity. In light of this convergence, I described what capabilities are at stake in the way pervasive captivity affects animals' well-being, and I took the cue from the focus of the Approach on agency to lay out its commitments to foster both coexistence and freedom within the city. I also argued that a tension underlying Nussbaum's treatment of conflicts between humans and wildlife,

and amidst animals themselves, should not lead to dismissing the significance of captivity as a form of diminishment of capabilities, but instead to a renewed emphasis on agency. The flourishing of creatures within the city requires securing the material, including ecological, conditions of their capabilities, with a focus on freedom as a central element of the good life. Respectful and intelligent, that sustainable and animal-friendly, urban design should follow from CA given its commitment to interspecies justice.

\section{References}


Animal Ethics. 2019. Introduction to urban welfare ecology. Animal-ethics.org. 20 December 2019.

$\mathrm{URL}=<\underline{\text { https://www.animal-ethics.org/introduction-to-urban-welfare-ecology- }}$ $\underline{\operatorname{research} />}$

Barnes, Elizabeth. 2009. Disability and adaptive preference. Philosophical Perspectives 23(1):1-22

Bekoff, Marc and Jessica Pierce. 2017. The Animals' Agenda: Freedom, Compassion, and Coexistence in the Human Age. Boston: Beacon Press

Benson, Etienne. 2013. The Urbanization of the Eastern Gray Squirrel in the United States, Journal of American History 100(3): 691-710

Bruckner, Donald W. 2009. In Defense of Adaptive Preferences. Philosophical Studies 142(3): 307-324

Cochrane, Alasdair. 2009. Do Animals Have an Interest in Liberty? Political Studies 57: 660-79

Cripps, Elizabeth. 2010. Saving the Polar Bear, Saving the World: Can the Capabilities Approach do Justice to Humans, Animals and Ecosystems? Res Publica, 16: 1-22

Delon, Nicolas. 2020. Pervasive Captivity and Urban Wildlife. Ethics, Policy \& Environment, DOI: 10.1080/21550085.2020.1848173

Delon, Nicolas. 2018. Animal agency, captivity, and meaning. The Harvard Review of Philosophy, 25(2018), 127-146. https://doi.org/10.5840/harvardreview201892519

Delon, Nicolas and Purves, Duncan. 2018. Wild Animal Suffering is Intractable. Journal of Agricultural and Environmental Ethics 31 (2):239-260

Donaldson, Sue, and Will Kymlicka. 2011. Zoopolis: A Political Theory of Animal Rights. Oxford: Oxford University Press

Donaldson, Sue, and Will Kymlicka. 2016. Between Wildness and Domestication: Rethinking 
Categories and Boundaries in Response to Animal Agency. In B. Bovenkerk and J. Keulartz (eds.), Animal Ethics in the Age of Humans: Blurring boundaries of human-animal relationships (Springer), pp. 225-39

Elster, Jon. 1983. Sour Grapes: Studies in the Subversion of Rationality. Cambridge: Cambridge University Press

Gehrt, Stanley. 2004. Ecology and management of striped skunks, raccoons, and coyotes in urban landscapes. In Fascione, N., Delach, A., and M. Smith (eds), People and predators: from conflict to conservation (Washington, DC: Island Press), pp. 81-104

Gehrt, S. D., Brown, J. L., and C. Anchor. 2011. Is the urban coyote a misanthropic synanthrope? The case from Chicago. Cities and the Environment 4(1)

Goodyear, Dana. 2017. Valley cats. The New Yorker, February 13 \& 20, 201, pp. 44-51

Gruen, Lori. 2002. Refocusing environmental ethics: From intrinsic value to endorsable valuations. Philosophy and Geography 5(2): 153-164

Gruen, Lori. 2011. Ethics and Animals. Cambridge: Cambridge University Press Gruen, Lori, ed. 2014a. The Ethics of Captivity. Oxford: Oxford University Press

Gruen, Lori. 2014b. Dignity, Captivity, and an Ethics of Sight. In Gruen, L. (ed.), The Ethics of Captivity. Oxford: Oxford University Press, pp. 231-247

Gruen, Lori. 2018. Incarceration, Liberty, and Dignity. In Andrew Linzey and Clair Linzey (eds.), The Palgrave Handbook of Practical Animal Ethics. Palgrave Macmillan, pp. 153-163

Gullo, A., Lassiter U., J. and Wolch. 1998. The cougar's tale. In Wolch, J., Emel, J. (eds), Animal Geographies (London: Verso), pp 139-161 
Hailwood, Simon. 2012. Bewildering Nussbaum: Capability Justice and Predation. The Journal of Political Philosophy, 20(3): 293-313

Holland, Breena. 2008. Justice and the environment in Nussbaum’s “Capabilities Approach”. Political Research Quarterly 61(2): 319-32

Horowitz, Alexandra. 2014. Canis Familiaris: Companion and captive. In L. Gruen, ed., The Ethics of Captivity (Oxford University Press, pp. 7-21)

Jamieson, Dale. 2017. Animals and ethics, agents and patients. In Kristin Andrews and Jacob Beck (eds.), The Routledge Handbook of Philosophy of Animal Minds, Routledge

Jamieson, Dale. 2003. Morality's Progress. Oxford: Oxford University Press

Jerolmack, Colin. 2013. The Global Pigeon. Chicago: The University of Chicago Press

Lowry, H., Lill, A. and B. B. M. Wong. 2013. Behavioural responses of wildlife to urban environments. Biological Reviews, 88(3): 537-549

Miranda, A. C., Schielzeth, H., Sonntag, T. and J. Partecke. 2013. Urbanization and its effects on personality traits: a result of microevolution or phenotypic plasticity? Global Change Biology 19: $2634-2644$

Nussbaum, Martha C. 2000. The Costs of Tragedy: Some Moral Limits of Cost-Benefit Analysis. Journal of Legal Studies, 29(2): 1005-1036

Nussbaum, Martha C. 2001a. Women and Human Development: The Capabilities Approach. Cambridge: Cambridge University Press

Nussbaum, Martha C. 2001b. Animal Rights: The Need for a Theoretical Basis. Harvard Law Review, 114(5): 1506-1549 
Nussbaum, Martha C. 2006. Frontiers of Justice: Disability, Nationality, Species Membership. Cambridge, MA: The Belknap Press

Nussbaum, Martha C. 2013. Political Emotions: Why Love Matters for Justice. Cambridge, MA: The Belknap Press

Palmer, Clare. 2001. "Taming the wild profusion of existing things"?: A study of Foucault, power, and human/animal relationships. Environmental Ethics 23 (4):339-358

Palmer, Clare. 2003a. Colonization, urbanization, and animals. Philosophy and Geography 6 (1):47-58

Palmer, Clare. 2003b. Placing animals in urban environmental ethics. Journal of Social Philosophy 34 (1):64-78

Palmer, Clare. 2010. Animal Ethics in Context. New York: Columbia University Press

Parfit, Derek. 1987. Reasons and Persons. Oxford: Clarendon Press

Philo, Chris. 1998. Animals, geography, and the city: Notes on inclusions and exclusions. In Wolch, J., Emel, J. (eds), Animal Geographies (London: Verso), pp. 51-71

Philo, Chris, and Chris Wilbert, eds. 2000. Animal Spaces, Beastly Places, London: Routledge

Rachels, James. 1976. Do Animals Have a Right to Liberty? In T. Regan and P. Singer (eds.), Animal Rights and Human Obligations (pp. 205-223), Englewood Cliffs: Prentice-Hall

Riley, Seth P. D. et al. 2006. A southern California freeway is a physical and social barrier to gene flow in carnivores. Molecular Ecology 15: 1733-1741

Riley, Seth P. D., Cassity Bromley, Robert H. Poppenga, Francisco A. Uzal, Lynn Whited, and Raymond M. Sauvajot. 2007. Anticoagulant Exposure and Notoedric Mange in Bobcats and 
Mountain Lions in Urban Southern California. Journal of Wildlife Management 71(6): 1874-84. https://doi.org/10.2193/2005-615

Schell, CJ, Young, JK, Lonsdorf, EV, Santymire, RM, Mateo, JM. 2018. Parental habituation to human disturbance over time reduces fear of humans in coyote offspring. Ecology and Evolution 8: 12965-80

Schmidt, Andreas T. 2015. Why animals have an interest in freedom. Historical Social Research, 40(4): 92-109

Schmidt, Andreas T. 2016. Abilities and the sources of unfreedom. Ethics 127(1): 179-207

Schilthuizen, Menno. 2018. Darwin Comes to Town: How the Urban Jungle Drives Evolution. New York: Picador.

Sebo, Jeff. 2017. Agency and Moral Status. The Journal of Moral Philosophy 14(1): 1-22

Sepp Tuul, Ujvari Beata, Ewald Paul W., Thomas Frédéric, and Giraudeau Mathieu. 2019. Urban environment and cancer in wildlife: available evidence and future research avenues.

Proceedings of the Royal Society B, 286(1894). http://doi.org/10.1098/rspb.2018.2434

Serieys, L.E.K., Lea, A., Pollinger, J.P., Riley, S.P.D. and Wayne, R.K. 2015. Disease and freeways drive genetic change in urban bobcat populations. Evolutionary Applications, 8: 75-92. doi: $\underline{10.1111 / \text { eva.12226 }}$

Sullivan, Robert. 2004. Rats: Observations on the History \& Habitat of the City's Most Unwanted Inhabitants. New York: Bloomsbury

Terlazzo, Rosa. 2017. Must Adaptive Preferences Be Prudentially Bad for Us? Journal of the American Philosophical Association 3(4): 412-429 
Wichert, Rachel and Nussbaum, M. C. 2019. The Legal Status of Whales and Dolphins: From Bentham to the Capabilities Approach. In L. Keleher \& S. Kosko (Eds.), Agency and Democracy in Development Ethics (pp. 259-288). Cambridge: Cambridge University Press. 